\title{
Estratégias para edifícios de escritórios energia zero no Brasil com ênfase em BIPV
}

\author{
Strategies towards Net Zero Energy Office Buildings in \\ Brazil with emphasis on BIPV
}

\begin{abstract}
Evelise Leite Didoné
Andreas Wagner

Fernando Oscar Ruttkay Pereira

Resumo

$\mathbf{E}$

sta pesquisa tem o objetivo de avaliar o potencial de transformação de edifícios de escritório brasileiros em edifícios energia zero (EEZ) em diferentes climas. $\mathrm{O}$ estudo foi baseado em simulações computacionais, e o desenvolvimento do modelo foi dividido em três etapas. A primeira etapa consistiu na avaliação do caso protótipo (edifício referencial), que representa uma tipologia de edifícios de escritórios no Brasil. A segunda etapa consistiu no desenvolvimento do caso otimizado (edifício com baixo consumo de energia) de acordo com o regulamento de eficiência energética brasileiro. O comportamento dos dois casos foi determinado e comparado com o cálculo do balanço térmico e energético do edifício. Finalmente, o caso energia zero foi obtido por meio da aplicação de tecnologias solares (BIPV) na edificação. As simulações computacionais foram realizadas através dos programas EnergyPlus e Daysim para Fortaleza, CE, e Florianópolis, SC, cidades localizadas em diferentes zonas climáticas do Brasil. Os resultados mostraram que, em Fortaleza, mais módulos fotovoltaicos foram necessários devido ao maior consumo de energia, principalmente com refrigeração. $\mathrm{O}$ uso do regulamento de eficiência energética proporcionou redução no consumo de aproximadamente 50\%. Porém, com o uso da janela fotovoltaica, outras estratégias foram necessárias para atingir o EEZ.
\end{abstract}

Palavras-chave: Eficiência energética. Edifícios energia zero. Fotovoltaicos (FV) semitransparente em janelas. Simulação computacional.

Evelise Leite Didoné Karlsruhe Intitute of Technology Karlsuhe - Alemanha

Andreas Wagner Karlsruhe Intitute of Technology Karlsuhe - Alemanha

Fernando Oscar Ruttkay Pereira Universidade Federal de Santa Catarina Florianópolis - SC - Brasil

Recebido em 04/06/13 Aceito em 07/05/14

\begin{abstract}
This research work aims to evaluate the potential to transform Brazilian office buildings into Zero Energy Buildings (ZEB) in different climates, based on computer simulations. The development of the model was divided into three steps. The first step was the evaluation of the prototype case (reference building), which represents the current building typology of Brazilian office buildings. The second step was the development of an optimal case (low energy building) according to the Brazilian energy efficiency labelling system. The performance of both cases was determined and compared by calculating the building's heat balance and energy balance. Finally, the ZEB case was obtained by the application of solar energy technologies (BIPV) in the building. The simulations were carried out with the computer programs EnergyPlus and Daysim for two cities in two different climatic zones of Brazil: Fortaleza/CE and Florianopolis/SC. The results showed that, in Fortaleza, more photovoltaic modules were necessary due to the higher energy consumption, especially for cooling. In addition, the application of the Brazilian energy efficiency regulation for buildings allowed a reduction of almost $50 \%$ in the final energy consumption. However, others strategies were also necessary to reach $Z E B$, due to the use of $P V$ windows.
\end{abstract}

Keywords: Energy efficiency. Zero energy buildings. Semi-transparent photovoltaic (PV) windows. Computer simulation. 


\section{Introdução}

Atualmente, as energias renováveis contribuem com $44 \%$ da matriz energética brasileira, um valor elevado em comparação aos $13 \%$ da média mundial. Entretanto, $82 \%$ dessa energia são provenientes das usinas hidroelétricas (MINISTÉRIO..., 2012). As hidroelétricas são baseadas em geração centralizada, com capacidade de crescimento limitada, e as longas distâncias entre o centro de geração e os centros de consumo causam elevados custos e perdas de energia.

No Brasil, os edifícios existentes são responsáveis por $47 \%$ do consumo de energia, distribuídos entre edifícios residenciais $(24 \%)$, comerciais $(15 \%)$ e públicos (8\%) (MINISTÉRIO..., 2012). Nos edifícios comercias e públicos os sistemas de ar condicionado e iluminação são os maiores consumidores (PROCEL, 2013). O elevado crescimento da demanda energética provém da estabilidade econômica em combinação com o crescimento da classe média, que aumentou o acesso da população às novas tecnologias que proporcionam bem-estar.

O setor de edificações tem alto consumo de eletricidade, mas também alto potencial de economia. Segundo Chidiac et al. (2011), a redução no consumo de energia em edificações existentes pode ser atingida com a implementação de medidas energéticas de retrofit. Em novos edifícios, a incorporação de tecnologias eficientes desde a concepção inicial do projeto pode resultar numa economia superior a $50 \%$, quando se compara com edifícios projetados sem o uso dessas tecnologias (PROCEL, 2013; LENOIR; THELLIER; GARDE, 2011a).

A grande disponibilidade de radiação solar no Brasil é um fator significante para o uso da energia solar e aplicação da tecnologia fotovoltaica (FV) no país (RÜTTER, 2004). Sistemas solares fotovoltaicos podem ser aplicados e/ou integrados no edifício e interligados à rede elétrica. Essa tecnologia vem-se tornando uma alternativa promissora para o futuro. Entretanto, alguns cuidados devem ser tomados quando os edifícios estão localizados em áreas urbanas, já que a área para a instalação dos sistemas fotovoltaicos é a envoltória dos edifícios, e sombras nos módulos devem ser evitadas, para não reduzir sua eficiência.

Os painéis solares podem ser integrados nas coberturas e fachadas, ou substituir elementos como as proteções solares. Atualmente, uma grande variedade de módulos fotovoltaicos com diferentes tecnologias está disponível no mercado (PETTER JELLE; BREIVIK; DROLSUM
RØKENES, 2012), o que oferece uma ampla opção para os arquitetos. Os custos dos módulos também estão diminuindo significativamente com o crescimento da produção dos painéis $\mathrm{FV}$ em escala industrial. Isso permite utilizá-los não apenas para gerar energia, mas também por motivos estéticos.

Combinando diferentes estratégias, os edifícios podem gerar e economizar energia, a ponto de tornar possível um balanço energético zero. Essas edificações são chamadas de edifícios energia zero (EEZ). O conceito do edifício energia zero já foi provado em países da Europa e nos Estados Unidos (LENOIR et al., 2014; MUSALL et al., 2010).

Este estudo tem como objetivo avaliar o potencial para a transformação de edifícios de escritório verticais no Brasil em EEZ utilizando métodos para a redução do consumo de energia e aplicação da tecnologia fotovoltaica em diferentes climas. A dificuldade em transformar edifícios verticais em EEZ vem do grande número de pavimentos, o que aumenta o consumo de eletricidade e, comparado com a área relativa disponível da envoltória, oferece menores possibilidades para a aplicação dos painéis fotovoltaicos, já que a área de cobertura é reduzida.

\section{Revisão de literatura Tecnologias fotovoltaicas em edifícios}

Há mais de 20 anos, o uso de sistemas fotovoltaicos vem sendo investigado em edifícios (HUMM; TOGGWEILER, 1993). Nos últimos cinco anos, essa tecnologia tem sido o segmento de mais rápido crescimento no mercado de geração de energia elétrica (SAWIN et al., 2011). A queda nos preços dos módulos fotovoltaicos, uma consequência dos novos mercados, associados à possibilidade de instalação de painéis fotovoltaicos no local onde a energia é consumida, e o desenvolvimento de módulos integrados ao edifício fazem do fotovoltaico uma tecnologia ideal para ambientes urbanos.

Entre as diferentes fontes de energias renováveis, a energia fotovoltaica e os coletores solares parecem mais adequados para ser utilizados nas envoltórias das edificações. Os componentes fotovoltaicos podem ser aplicados na envoltória dos edifícios de diferentes maneiras: integrados ao edifício (Building-Integrated $P V$ - BIPV) e adicionados/anexados ao edifício (BuildingAdded/Attached PV - BAPV). Os produtos BAPV 
requerem sistemas de montagem adicionais e são normalmente utilizados em retrofit, enquanto os produtos BIPV tornam-se parte integrante da envoltória do edifício e podem substituir completamente componentes da envoltória.

O componente fotovoltaico pode ser usado em coberturas, superfícies opacas e semitransparentes, como função estrutural, proteção solar e revestimento, e assim reduzir os custos da construção. O potencial de diferentes tipologias de edifícios com integração $\mathrm{FV}$, observações para otimizar o desempenho energético e maximizar a contribuição do FV na geração de energia, bem como a aplicação da nova tecnologia de filme fino e seus componentes, como as células semitransparentes integradas nos vidros, podem ser encontrados na literatura (HAYTER; TORCELLINI; DERU, 2002; MERCALDO et al., 2009; DIDONÉ; WAGNER, 2013).

Um exemplo de aplicação real pode ser encontrado na Oslo Opera House (FORNYBAR, 2010), que tem uma grande fachada de vidro com fotovoltaico semitransparente, o qual é, ao mesmo tempo, um dispositivo estético e de sombreamento. Outro caso é a fachada oeste do futuro Centro de Convenções da EPFL (BARRAUD, 2012), na Suíça, que foi construído com as janelas de painéis fotovoltaicos translúcidos e coloridos.

Do ponto de vista arquitetônico, os edifícios citados mostram que o semitransparente BIPV pode alcançar benefícios estéticos mediante o uso de módulos fotovoltaicos multifuncionais. No entanto, em termos de geração de energia, sua contribuição para a demanda global do edifício ainda é pequena, devido à baixa eficiência dos módulos de filme fino em relação aos módulos cristalinos (MERCALDO et al., 2009). Resumindo, a redução significativa no custo dos módulos oferece a possibilidade de utilizá-los não apenas para a geração de energia, mas também por razões estéticas, quando a geração de energia elétrica se torna um benefício.

\section{Edifício Energia Zero - EEZ (Zero Energy Building - ZEB)}

Nos últimos anos, o tema edifícios energia zero (EEZ) tem recebido atenção crescente. Em 2010, a Comissão Europeia e o Parlamento aprovaram a reformulação da diretiva relativa ao desempenho energético dos edifícios (EPDB), que exige que até o final de 2020 todos os novos edifícios sejam edifícios quase energia zero ${ }^{1}$ (EUROPEAN..., 2010). Já o Departamento de Energia dos EUA

${ }^{1}$ Edifícios quase energia zero possuem um consumo energético muito baixo (EUROPEAN..., 2010).
(DOE) estabeleceu a meta para alcançar casas energia zero até 2020, e edifícios comerciais energia zero até 2025 (UNITED..., 2014).

Até o início de 2011, nenhum código nacional de energia definiu um EEZ explicitamente (VOSS; MUSALL; LICHTMEß, 2011). No entanto, diferentes conceitos foram desenvolvidos em relação ao cálculo do balanço energético anual para os EEZs (TORCELLINI et al., 2006; VOSS; MUSALL; LICHTMEß, 2011; LENOIR et al., 2014). Torcellini et al. (2006) exploraram o conceito de edifícios energia zero nas atuais construções de baixo consumo energético. As quatro definições são: energia local zero (net zero site energy), fonte de energia zero (net zero source energy), custos de energia zero (net zero energy costs) e emissão zero (net zero emissions). Para outros autores, um edifício energia zero é simplesmente um resultado neutro para o balanço energético e/ou de emissões durante o período de 1 ano (VOSS; MUSALL; LICHTMEß, 2011; SARTORI et al., 2010).

Para um melhor entendimento dos edifícios energia zero, vários países da Europa, EUA, Canadá e Nova Zelândia estão participando de um projeto chamado "Rumo aos Edifícios Solares Energia Zero" (Towards Net Zero Energy Solar Buildings), da IEA SHC Task 40/ECBCS (SHC..., 2008). Os objetivos do projeto são estudar os atuais edifícios energia zero, quase energia zero e os edifícios com baixo consumo energético, para desenvolver um entendimento comum de definições, ferramentas, soluções inovadoras e produção industrial.

O Enerpos, projeto de pesquisa francês, se centrou no desenvolvimento de novos métodos e ferramentas para a concepção de edifícios de energia zero em climas quentes. $\mathrm{O}$ método proposto foi aplicado para o primeiro EEZ nos territórios ultramarinos franceses. $\mathrm{O}$ edifício foi projetado para funcionar o maior tempo possível utilizando técnicas passivas, como ventilação natural cruzada e iluminação natural. $\mathrm{O}$ objetivo de atingir um consumo de energia menor do que 50 $\mathrm{kWh} /\left(\mathrm{m}^{2}\right.$.ano), três vezes inferior à média dos edifícios padrão locais, foi obtido por simulações computacionais, e o consumo real de energia elétrica depois de 1 ano de operação foi em torno de $31 \mathrm{kWh} /\left(\mathrm{m}^{2}\right.$.ano), que é $38 \%$ menor; o fornecimento com fotovoltaicos foi de 78 $\mathrm{kWh} /\left(\mathrm{m}^{2}\right.$.ano) (LENOIR et al., 2014; LENOIR; THELLIER; GARDE, 2014).

$\mathrm{O}$ número de edifícios que atingem energia zero está crescendo continuamente em todo o mundo (NASA, 2013). Com o aumento de soluções técnicas mais eficientes, diferentes tipos de 
edifícios (educacionais, comerciais, residenciais) vêm sendo construídos como EEZ, sendo a maioria em países e climas do hemisfério Norte do globo. Até agora, na América do Sul, o único EEZ existente está localizado na Argentina.

\section{Contexto brasileiro: edifícios energeticamente eficientes}

O maior passo em torno da eficiência energética no Brasil foi a aprovação da primeira iniciativa para promover a eficiência energética através da Lei ${ }^{\circ}$ 10.295, de outubro de 2001 (BRASIL, 2001). Esse ato reforçou o Programa Nacional de Conservação de Energia Elétrica do Brasil (Procel), que lançou seu plano para eficiência energética de edifícios em 2003.

Um dos resultados desse plano foi o sistema de etiquetagem de eficiência energética chamado Regulamento Técnico da Qualidade dos Edifícios Comerciais, de Serviços e Públicos (RTQ-C), publicado em 2009 (BRASIL, 2010), e sua sequência com o Regulamento Técnico da Qualidade de Edifícios Residenciais (RTQ-R), em 2010 (BRASIL, 2012). Ambos os regulamentos definem uma metodologia para classificar o nível de eficiência energética dos edifícios.

A aplicação da energia solar fotovoltaica no Brasil começou a ser discutida no início desta década. No entanto, o primeiro sistema de geração do país foi instalado em 1997, na Universidade Federal de Santa Catarina (UFSC), pelo Grupo de Pesquisa Estratégica em Energia Solar (FV-UFSC). Outros sistemas também foram instalados nas universidades de São Paulo (USP), do Rio Grande do Sul (UFRGS) e do Pará (UFPA), bem como em institutos de pesquisa e serviços públicos. O sistema fotovoltaico instalado ajuda a gerar energia para o prédio, mas o balanço energético não chega a zero. Enquanto isso, novos projetos vêm sendo desenvolvidos, tais como a concepção de estádios solares (Copa do Mundo de 2014) e os aeroportos solares.

Outro avanço é a aprovação da Resolução Normativa $\mathrm{n}^{\circ}$ 482, em abril de 2012, da Agência Nacional de Energia Elétrica (Aneel). A resolução regulamenta a micro e minigeração de energia por parte dos consumidores (AGÊNCIA..., 2012). Isso significa que qualquer um pode instalar um sistema gerador e usar sua própria energia. A energia não utilizada pode ser exportada para a rede elétrica e, assim, reduzir a fatura energética.

Até o momento, EEZs não existem no Brasil. Do ponto de vista econômico, a geração de energia renovável no local (on site), como a energia solar e a eólica, ainda sofre com os altos custos de investimento. No entanto, dois projetos EEZ institucionais já foram desenvolvidos: o Cecas, edifício que será o Centro de Estudos de Clima e Ambientes Sustentáveis da Universidade de São Paulo, e a EKÓ House. Este último participou, em 2012, do Solar Decathlon (SD EUROPA, 2012), na Europa, uma competição universitária internacional com o objetivo de projetar uma casa energeticamente eficiente e inovadora, onde os ocupantes são abastecidos exclusivamente com energia solar.

\section{Metodologia}

Esta pesquisa foi baseada em simulações computacionais. Para transformar edifícios em EEZs, uma série de medidas devem ser tomadas. Para isso, um processo metodológico combinando estratégias para a redução do consumo energético e aplicação de tecnologia para geração de energia foi desenvolvido, em três etapas: caso protótipo, caso otimizado e caso energia zero. Essas etapas correspondem ao desenvolvimento da edificação para se tornar um edifício energia zero. A Figura 1 apresenta as etapas percorridas e sua sequência.

Figura 1 - Fluxograma do desenvolvimento do modelo

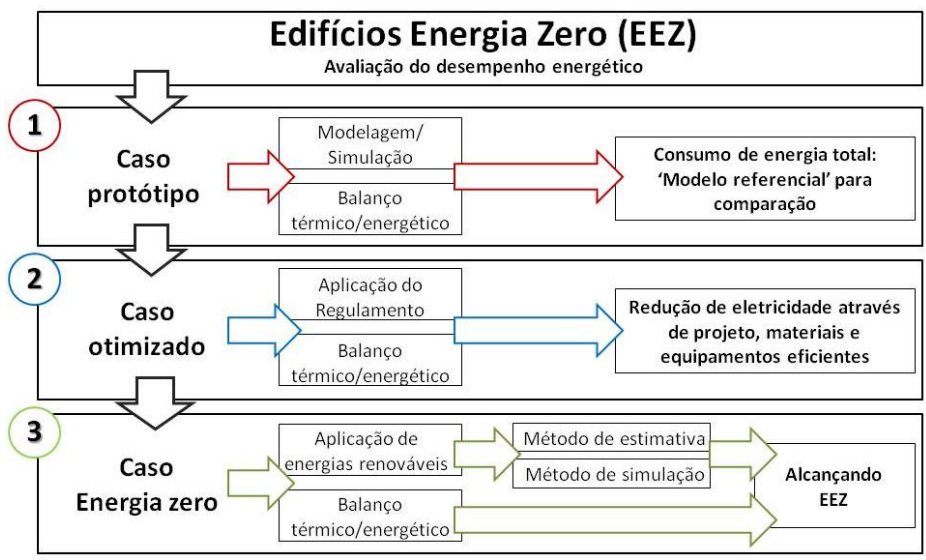

30 Didoné, E. L.; Wagner, A.; Pereira, F. O. R. 


\section{Definição do caso protótipo}

Um modelo representativo de edifício de escritórios brasileiro foi definido com base em informações bibliográficas (CARLO, 2008; SANTANA, 2006). As características construtivas, materiais e cargas internas foram obtidos a partir de estudos anteriores (SANTANA, 2006). O edifício vertical é composto de cinco salas de escritório e um corredor lateral, com dimensões de $25 \mathrm{~m} \mathrm{x} 8 \mathrm{~m}$ e altura total de $29,7 \mathrm{~m}$. O edifício possui onze pavimentos com $200 \mathrm{~m}^{2}$ por andar (Figura 2). Nas aberturas, janelas com vidro incolor de $6 \mathrm{~mm}$ foram utilizadas.

$\mathrm{O}$ prédio é ocupado das $8 \mathrm{~h}$ às $18 \mathrm{~h}$, com 14,7 $\mathrm{m}^{2}$ /pessoa nos escritórios. O ganho interno para equipamentos é $9,7 \mathrm{~W} / \mathrm{m}^{2}$. O sistema de ar condicionado é composto de um split em cada escritório, com coeficiente de performance (COP) de 2,8 e setpoint para aquecimento de $18{ }^{\circ} \mathrm{C}$, e de $24{ }^{\circ} \mathrm{C}$ para resfriamento (SANTANA, 2006). O ganho interno de iluminação artificial foi baseado nos valores exigidos pela ASHRAE (AMERICAN..., 2005): $12 \mathrm{~W} / \mathrm{m}^{2}$ para escritórios e $5 \mathrm{~W} / \mathrm{m}^{2}$ para a circulação. A circulação é ocupada por 1 pessoa, e o ganho interno corresponde aos elevadores em tráfego e standby.

As superfícies internas (teto, paredes e piso) foram consideradas com refletâncias de 0,80, 0,50 e 0,20 respectivamente, dados necessários para a simulação de iluminação natural no Daysim.

O modelo foi avaliado com a maior fachada orientada para Norte-Sul, com o corredor voltado para Norte e os escritórios para Sul. Esta posição foi escolhida para uma melhor aplicação dos elementos fotovoltaicos, visto que se pretende avaliar o potencial das janelas com fotovoltaico na obtenção do EEZ. O entorno não foi considerado.
O caso protótipo representa uma das tipologias existentes de edifício de escritórios no Brasil. Através desta análise foi possível obter o consumo total de energia do edifício para o desenvolvimento dos demais casos (caso otimizado e caso energia zero).

\section{Simulação de edificações}

O consumo energético foi obtido mediante simulação computacional a partir de dois programas: Daysim e EnergyPlus. O Daysim foi utilizado para avaliar o comportamento da luz natural e obter os dados de iluminação artificial para a simulação integrada com o EnergyPlus, utilizado para a obtenção do consumo energético total (DIDONÉ, 2009).

Para os modelos que utilizam o controle de iluminação artificial, os dados obtidos pelo Daysim foram utilizados como dados de entrada para a simulação termoenergética no EnergyPlus. O Daysim fornece dados horários para a ativação da iluminação artificial por meio de um controle automático. Utilizou-se um sistema de controle dimmerizável mediante um sensor fotoelétrico.

As simulações foram realizadas para duas cidades brasileiras que representam diferentes zonas bioclimáticas. Fortaleza, CE, na zona bioclimática 8, está localizada próximo à linha do Equador, com clima tropical (latitude $3^{\circ} 78^{\prime} \mathrm{S}$ ), e é uma das cidades brasileiras com valores elevados de irradiação solar, cuja média diária é de 5,67 $\mathrm{kWh} / \mathrm{m}^{2}$. Florianópolis, SC, na zona bioclimática 3 , situa-se no Sul do país (latitude $27^{\circ} 67^{\prime} \mathrm{S}$ ) e apresenta os menores valores de irradiação solar, com média diária de $4,77 \mathrm{kWh} / \mathrm{m}^{2}$ (LABORATÓRIO..., 2013). Os arquivos climáticos utilizados nas simulações foram obtidos no site do Departamento de Energia dos EUA (UNITED..., 2012).

Figura 2 - (a) Perspectiva e (b) planta baixa do edifício de escritório representativo

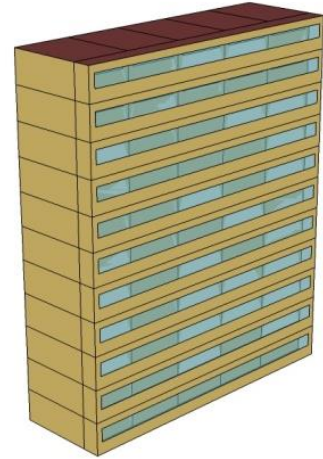

(a)

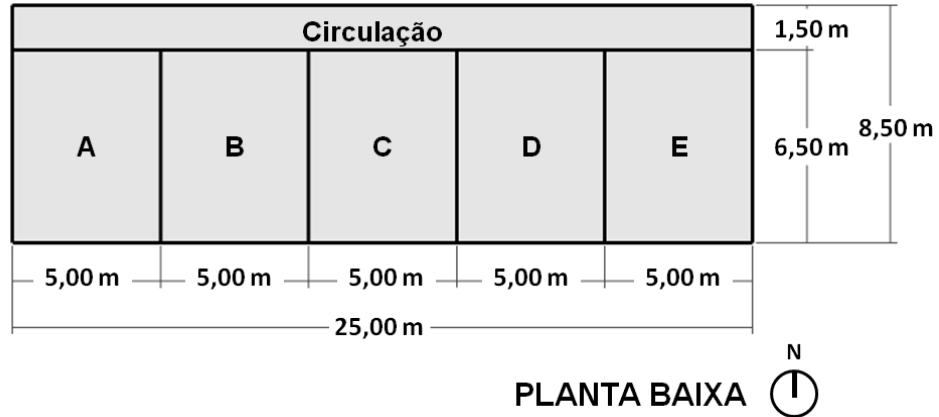

(b) 


\section{Análise do edifício}

$\mathrm{O}$ desempenho dos casos foi determinado e comparado através do balanço termoenergético. $\mathrm{O}$ balanço térmico foi realizado para todo o edifício através de dados de saída do EnergyPlus. O programa considera a condução de calor, a convecção e radiação entre superfícies internas e o ambiente externo com saídas detalhadas sobre as diferentes superfícies do edifício (cobertura, pavimentos intermediários, piso, paredes e janelas), além dos ganhos internos como infiltração, refrigeração, aquecimento, iluminação, pessoas e equipamentos (ENERGYPLUS, 2012b). A análise do balanço térmico permite investigar as trocas de calor pelas superfícies e os ganhos internos para reduzir o consumo do ar condicionado, que no Brasil é um dos responsáveis pelo alto consumo de energia.

Com o balanço energético, a energia total consumida e produzida no edifício pode ser avaliada. O EnergyPlus fornece informações sobre a energia final utilizada pelos equipamentos, iluminação, refrigeração, aquecimento e ventilação, e a energia gerada pelos painéis fotovoltaicos na cobertura, fachadas, janelas e proteções solares. A energia gerada pela janela com fotovoltaico foi calculada separadamente (ver tópico Geração de energia pela janela com fotovoltaico semitransparente).

\section{BIPV e BAPV: aplicação e cálculo}

Para o desenvolvimento de EEZ, a redução do consumo de energia é um passo necessário, mas não suficiente; a energia elétrica deve ser gerada. Este tópico apresenta as tecnologias FV utilizadas e os cálculos para geração de energia elétrica.

\section{Seleção dos módulos fotovoltaicos}

Diversas tecnologias fotovoltaicas foram escolhidas para ser utilizadas na envoltória do edifício. As células solares selecionadas de módulos cristalino (m-Si) e filme fino (CIS) possuem a maior eficiência disponível no mercado hoje. Os painéis de $\mathrm{m}$-Si foram utilizados na cobertura, e o CSI, na fachada e proteção solar. A célula solar orgânica $(\mathrm{OPV})$ foi selecionada devido a sua característica semitransparente homogênea e a seu alto potencial para integração na janela (COLSMANN et al., 2011) (Tabela 1). Além disso, as células solares orgânicas encapsuladas apresentam potencial de baixos custos de produção e em breve estarão disponíveis no mercado. A escolha por uma nova tecnologia tem o intuito de inovar com a avaliação de seu potencial para futuras aplicações.

$\mathrm{O}$ modelo possui o máximo de módulos FV possível em sua cobertura e $90 \%$ da área das fachadas leste e oeste com módulos fotovoltaicos; $100 \%$ das aberturas da fachada norte e da proteção solar da fachada sul, quando for o caso. $\mathrm{Na}$ cobertura, os módulos foram aplicados com inclinação de $27^{\circ}$ em Florianópolis e de $3^{\circ}$ em Fortaleza (a inclinação igual à latitude local proporciona altos valores de irradiação solar no módulo). Em ambos os casos, os módulos da cobertura foram orientados a norte. Nas fachadas e janelas, os módulos fotovoltaicos foram analisados com uma inclinação de $90^{\circ}$, ou seja, no mesmo plano da fachada. Já nas proteções solares, os painéis foram aplicados na horizontal (inclinação de $0^{\circ}$ ), a mesma da proteção solar.

\section{Cálculo da geração de energia}

Os valores de irradiação solar diária foram utilizados para calcular a energia elétrica gerada pelos métodos de estimativa e de simulação.

Tabela 1 - Características dos fotovoltaicos

\begin{tabular}{|c|c|c|c|c|c|c|c|c|}
\hline \multicolumn{8}{|c|}{ Dados do fabricante } & \multirow{2}{*}{$\begin{array}{c}\text { Calculado } \\
\text { EFF }_{\text {NOCT }} \\
{[\%]}\end{array}$} \\
\hline Aplicação & Tecnologia & Fabricante & Modelo & $\begin{array}{c}\text { Área } \\
\text { do } \\
\text { módulo } \\
{\left[\mathbf{m}^{2}\right]} \\
\end{array}$ & $\begin{array}{c}\text { Powe } \\
\mathbf{r} \\
{[\mathbf{W}]}\end{array}$ & $\begin{array}{c}\mathbf{E F F}_{\mathrm{STC}} \\
{[\%]}\end{array}$ & $\begin{array}{c}k_{\text {temp }} \\
{\left[\% /^{\circ}\right.} \\
\text { C }]\end{array}$ & \\
\hline Cobertura & $\mathrm{m}-\mathrm{Si}$ & Sunpower & $\begin{array}{l}\text { SPR-435- } \\
\text { NE-WHT-D }\end{array}$ & 2,16 & 435 & 20,1 & $-0,38$ & 18,6 \\
\hline $\begin{array}{l}\text { Fachada/ } \\
\text { Prot. solar }\end{array}$ & CIS & $\begin{array}{c}\text { Solar } \\
\text { Frontier }\end{array}$ & SF-160-S & 1,2 & 160 & 13 & $-0,31$ & 12,2 \\
\hline Janela & $\begin{array}{l}\text { Orgânico } \\
\text { (OPV) }\end{array}$ & Laboratório & - & - & - & 3 & $+0,05$ & - \\
\hline
\end{tabular}

32 Didoné, E. L.; Wagner, A.; Pereira, F. O. R. 


\section{Estimativa da geração de energia}

Existem diferentes métodos para estimar a energia gerada por fotovoltaico em edifícios. Neste estudo utilizou-se o método da potência instalada. Os módulos fotovoltaicos foram distribuídos sobre a área disponível do prédio (cobertura, fachada e proteção solar). Espaços foram deixados vazios para o acesso, cabos, instalação e manutenção. $\mathrm{O}$ número de módulos foi multiplicado pela potência nominal dos módulos fotovoltaicos, usando-se a Equação 1, e a energia gerada foi calculada usando-se a Equação 2 (ZOMER, 2012).

$P_{\text {inst }}=n P_{\text {nom }}$

Eq. 1

$W_{\text {el }}=E_{\text {did }} / E_{\text {STC }} k_{\text {eff }} P_{\text {inst }}$

Eq. 2

Onde:

$P_{\text {inst }}$ é a potência instalada em $\mathrm{kW}$;

n é o número de módulos;

$P_{n o m}$ é a potência nominal do módulo em kW (para as condições normais de teste);

$W_{e l}$ é a eletricidade gerada em $\mathrm{kWh} / \mathrm{dia}$;

$E_{d i a}$ é a irradiação solar no módulo em $\mathrm{kWh} /\left(\mathrm{m}^{2}\right.$ dia);

$E_{S T C}$ é a radiação solar para as condições normais de teste $\left(1 \mathrm{~kW} / \mathrm{m}^{2}\right)$; e

$k_{\text {eff }}$ é o desempenho do sistema de inversor e conexões.

Para este estudo utilizou-se um desempenho de 0,85 , por estar entre os valores recomendados na literatura (ZOMER, 2012).

A irradiação solar diária para cada mês do ano foi obtida pelo programa Radiasol, que calcula a radiação solar incidente para superfícies horizontais e inclinadas para todas as orientações, de acordo com a latitude e a inclinação dada como valores de entrada.

A maioria das tecnologias fotovoltaicas tem diminuição em sua potência de saída com o aumento da temperatura de operação. Este é o caso das células do cristalino $(\mathrm{m}-\mathrm{Si})$ e do filme fino (CIS). Para esses modelos, a eficiência corrigida $\left(E F F_{N O C T}\right)$ foi calculada pela Equação 3. Estes valores foram utilizados para o cálculo da estimativa da geração de energia (Tabela 1). Para o método de simulação, o programa EnergyPlus faz o cálculo.

$E F F_{N O C T}=E F F_{S T C}\left[\frac{100-\left(\left|k_{t e m p}\right| \Delta T\right)}{100}\right]$

Eq. 3

Onde:

$E F F_{N O C T}$ é a eficiência corrigida para uma temperatura de operação de $45^{\circ} \mathrm{C}$;
$E F F_{S T C}$ é a eficiência normalizada do módulo;

$k_{\text {temp }}$ é o coeficiente de temperatura; e

$\Delta \mathrm{T}$ é a diferença de temperatura entre as condições de teste padrão (STC) e a temperatura de operação do módulo NOCT.

Para uma temperatura de operação maior do que $25{ }^{\circ} \mathrm{C}$ da STC, um NOCT de $45^{\circ} \mathrm{C}$ e um $\Delta \mathrm{T}$ de 20 ${ }^{\circ} \mathrm{C}$ foram usados (ZOMER, 2012).

\section{Simulação da geração de energia}

O EnergyPlus oferece três algoritmos matemáticos diferentes para o cálculo da eletricidade produzida por um painel fotovoltaico. Os algoritmos são: simples; um-diodo equivalente; e Sandia (ENERGYPLUS, 2012a). Para este estudo foi utilizado o objeto simples, que é útil no cálculo da geração anual de energia na fase de projeto. O programa calcula a radiação solar incidente dependendo da inclinação do módulo e orientação, considerando sombreamento e reflexões.

\section{Geração de energia pela janela com fotovoltaico semitransparente}

As janelas com fotovoltaico semitransparente consistem em uma janela de vidro duplo, com fotovoltaico orgânico encapsulado entre as duas placas de vidro. Os vidros possuem $3 \mathrm{~mm}$ de espessura e são separados por uma camada de ar de $12 \mathrm{~mm}$. A célula fotovoltaica é aplicada no lado interior do vidro exterior. Para o vidro interior, um $l o w-E$ foi selecionado, a fim de prevenir que o calor gerado pelo fotovoltaico seja irradiado para o ambiente (Figura 3). O fotovoltaico orgânico tem eficiência de $3 \%$. A janela possui transmitância térmica de $1,67 \mathrm{~W} /\left(\mathrm{m}^{2} . \mathrm{K}\right)$, transmitância visível de $23 \%$ e fator solar de $22 \%$ (LICHTTECHNISCHES..., 2012).

Como não é possível calcular diretamente a eletricidade gerada pelo fotovoltaico semitransparente da janela no EnergyPlus (ENERGYPLUS, 2012a), foi necessário calcular a energia gerada pela janela com FV e o consumo de energia total anual separadamente. Para isso, foram feitos cálculos para extrair as temperaturas no interior (núcleo) da janela, que podem ser acessados mais detalhadamente em Didoné e Wagner (2013). A energia gerada foi calculada multiplicando-se o resultado da Equação 4 pela área da janela.

$q_{-}$el $=q_{-}$sol $(1-\alpha)(1-\rho) n_{-} P V[1+$

$k_{-}$temp $\left.\left(\vartheta_{-} P V-25\right)\right]$

Eq. 4

Onde:

$\alpha$ é a absorção; 
$\rho$ é a reflexão;

$n_{P V}$ é a eficiência da célula solar;

$k_{\text {temp }}$ é o coeficiente de potência da temperatura de saída (obtido a partir do fabricante);

$\vartheta_{P V}$ é a temperatura da célula solar em ${ }^{\circ} \mathrm{C}$;

$\dot{q}_{s o l}$ é a radiação solar em $\mathrm{W} / \mathrm{m}^{2}$; e

$\dot{q}_{e l}$ é a eletricidade gerada em $\mathrm{W} / \mathrm{m}^{2}$.

\section{Resultados}

Este item apresenta o desenvolvimento do protótipo nos casos otimizado e energia zero, bem como a energia consumida e a energia gerada para todos os casos em análise.

\section{Desenvolvimento dos casos otimizado e energia zero}

Algumas etapas foram necessárias para se obter o edifício energia zero do caso protótipo (ineficiente). Inicialmente, o caso protótipo foi transformado em caso otimizado (baixo consumo de energia), com o intuito de minimizar sua demanda energética. $\mathrm{Na}$ sequência, painéis fotovoltaicos foram aplicados na envoltória, para gerar a energia necessária para atingir um balanço energético anual igual a zero.

\section{Caso otimizado}

Primeiramente, a envoltória e os ganhos internos do caso protótipo foram avaliados através do cálculo do balanço térmico. Com esse cálculo pode-se identificar os maiores ganhos de calor que influenciam no consumo do ar condicionado. O balanço térmico tem o objetivo de avaliar o fluxo de calor que entra e sai do ambiente, a fim de propor melhorias que reduzam o consumo energético. A Figura 4 mostra o balanço térmico detalhado, entre ganhos e perdas de calor, para o caso protótipo no período de um ano. A análise foi feita no período de ocupação ( $8 \mathrm{~h}-18 \mathrm{~h}$ ), com barras vermelhas, e durante o dia inteiro $(24 \mathrm{~h})$, com barras pretas.

O caso otimizado foi desenvolvido a partir do caso protótipo, de acordo com os requisitos necessários para atingir uma etiqueta A para envoltória, iluminação e ar condicionado, segundo o Regulamento Brasileiro de Eficiência Energética em Edificações (RTQ-C) (BRASIL, 2010).

Figura 3 - Modelo esquemático da janela com FV semitransparente

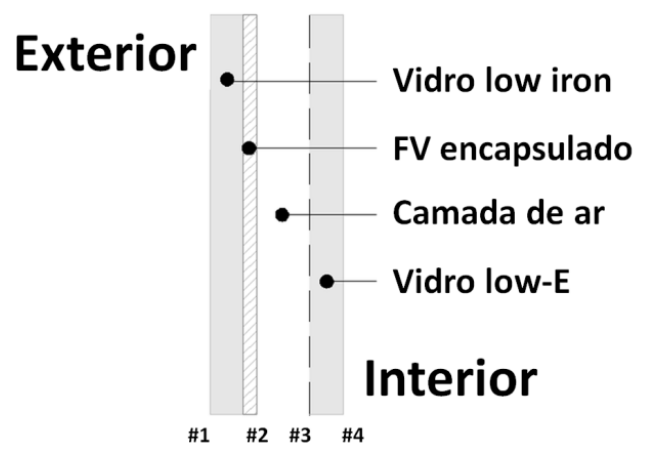

Figura 4 - Balanço térmico do edifício para o caso protótipo em (a) Florianópolis e (b) Fortaleza

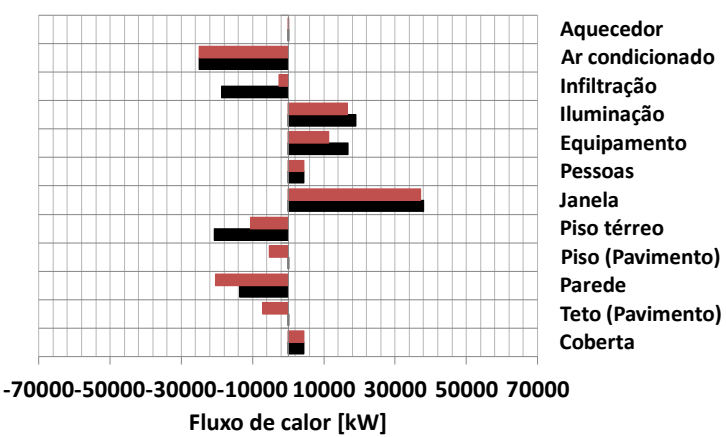

Fluxo de calor $[\mathrm{kW}]$

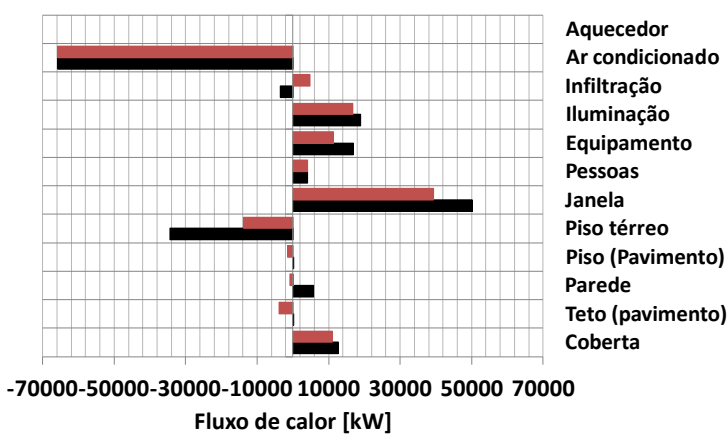

Fluxo de calor $[\mathrm{kW}]$ (a)

Período de ocupação (b)

34 Didoné, E. L.; Wagner, A.; Pereira, F. O. R. 


\section{Envoltória}

Para a transmitância térmica das paredes externas adotaram-se $3,1 \mathrm{~W} / \mathrm{m}^{2} . \mathrm{K}$ em Florianópolis e 0,39 $\mathrm{W} / \mathrm{m}^{2} . \mathrm{K}$ em Fortaleza. $\mathrm{Na}$ cobertura a transmitância de $0,25 \mathrm{~W} / \mathrm{m}^{2} . \mathrm{K}$ foi utilizada em ambas as cidades, bem como absortância de 0,25 nas paredes e cobertura. Esses valores foram definidos de acordo com a literatura (SANTANA, 2006; ABNT, 2003) e confirmados através de simulação computacional, com base nas características climáticas das cidades localizadas em diferentes zonas bioclimáticas do país.

As janelas externas dos escritórios foram aumentadas de um percentual de abertura na fachada (PAF) de $20 \%$ para $30 \%$, priorizando o uso da iluminação natural para atingir os 500 lux na área de trabalho. A janela com vidro simples foi substituída por janelas com vidro duplo low-E, e janelas altas foram inseridas na parede interna do escritório com a circulação.

Proteções solares foram acrescentadas para proteger as aberturas da radiação solar e dos ganhos de calor no período das $8 \mathrm{~h}$ às $16 \mathrm{~h}$. Para simulações em Florianópolis foram acrescentadas proteções solares horizontais às janelas dos corredores, e em Fortaleza, proteções horizontais e verticais. Para as janelas dos escritórios orientadas para sul em Fortaleza, utilizaram-se proteção solar horizontal e venezianas móveis.

\section{Iluminação}

Para aumentar a disponibilidade de luz natural nos escritórios, janelas altas com vidro incolor foram inseridas na parede entre o escritório e o corredor. A potência instalada de iluminação artificial foi substituída de $12 \mathrm{~W} / \mathrm{m}^{2}$ para $9,69 \mathrm{~W} / \mathrm{m}^{2}$, valor mínimo requerido pelo RTQ-C para obtenção do nível A em escritórios.

Além disso, um sistema com dimmerizador para controlar a iluminação artificial foi utilizado, a fim de assegurar que a iluminação artificial seja desligada quando a luz natural atingir 500 lux no escritório e 100 lux no corredor (INTERNATIONAL..., 2002).

\section{Ar-condicionado}

O ar-condicionado com COP de 4,31 foi selecionado na lista do PBE/Inmetro (INSTITUTO..., 2014) para substituir o arcondicionado utilizado no caso protótipo com COP de 2,8 .

A Figura 5 apresenta o balanço térmico obtido com a transformação do caso protótipo no caso otimizado. O ganho de calor da cobertura do caso protótipo foi reduzido com a troca de materiais. Em relação ao desenvolvimento do edifício através dos diferentes casos, a redução com iluminação e resfriamento foram os mais elevados. A redução do ar condicionado se deu principalmente pela redução dos ganhos das janelas.

\section{Caso Energia Zero}

O caso energia zero (EEZ) foi alcançado com a aplicação de tecnologias de energia solar na envoltória do edifício do caso otimizado. Módulos fotovoltaicos foram aplicados como BAPV na cobertura e BIPV nas fachadas leste e oeste (ver tópico Seleção dos módulos fotovoltaicos); janelas com painel fotovoltaico semitransparente foram utilizadas na fachada norte; e em Fortaleza módulos fotovoltaicos foram utilizados na proteção solar na fachada sul.

Figura 5 - Balanço térmico do edifício para o caso otimizado em (a) Florianópolis e (b) Fortaleza

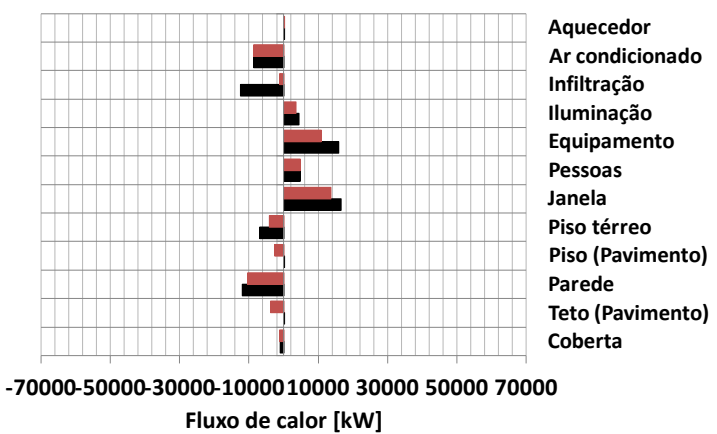

Fluxo de calor $[\mathrm{kW}]$

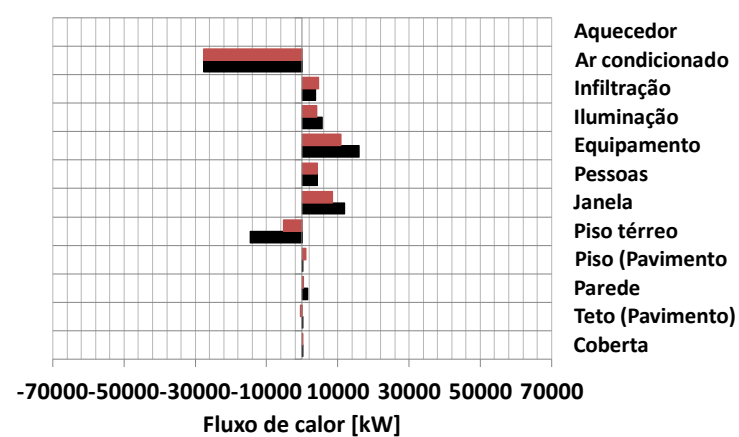

Fluxo de calor $[\mathrm{kW}]$

(a)

(b) 
O PAF das janelas dos corredores foi aumentado de $20 \%$ para $90 \%$, onde as janelas com fotovoltaico semitransparente foram aplicadas com o intuito de proteção solar e geração de eletricidade, já que o fator solar foi reduzido de 0,40 para 0,22. A janela interna, entre os escritórios e o corredor, teve o vidro incolor substituído pelo vidro low-E. Isolamento térmico foi adicionado à parede interna entre o corredor $\mathrm{e}$ os escritórios.

As características detalhadas dos modelos para cada caso e cidade que foram modificados ao longo do desenvolvimento dos casos estão apresentadas na Tabela 2; os outros parâmetros permaneceram constantes durante as simulações.

Tabela 2 - Características dos modelos

\begin{tabular}{|c|c|c|c|c|c|c|}
\hline Casos & \multicolumn{2}{|c|}{ Caso Protótipo } & \multicolumn{2}{|c|}{ Caso Otimizado } & \multicolumn{2}{|c|}{ Caso Energia Zero } \\
\hline \multicolumn{7}{|l|}{ Parâmetros } \\
\hline Cidade & Florianópolis & Fortaleza & Florianópolis & Fortaleza & Florianópolis & Fortaleza \\
\hline $\mathrm{PAF}_{\text {Corredor }}(\%)$ & 20 & 20 & 20 & 20 & 90 & 90 \\
\hline $\mathrm{PAF}_{\text {Escritório }}(\%)$ & 20 & 20 & 30 & 30 & 30 & 30 \\
\hline $\mathrm{U}_{\text {Janela sala }}\left[\mathrm{W} / \mathrm{m}^{2} . \mathrm{K}\right]$ & 5,82 & 5,82 & 1,68 & 1,68 & 1,68 & 1,68 \\
\hline $\mathrm{TV}_{\text {Janela sala }}$ & 0,88 & 0,88 & 0,70 & 0,70 & 0,70 & 0,70 \\
\hline $\mathrm{FS}_{\text {Janela sala }}$ & 0,82 & 0,82 & 0,40 & 0,40 & 0,40 & 0,40 \\
\hline $\mathrm{U}_{\text {Janela corredor }}\left[\mathrm{W} / \mathrm{m}^{2} . \mathrm{K}\right]$ & 5,82 & 5,82 & 1,68 & 1,68 & 1,67 & 1,67 \\
\hline $\mathrm{TV}_{\text {Janela corredor }}$ & 0,88 & 0,88 & 0,70 & 0,70 & 0,23 & 0,23 \\
\hline $\mathrm{FS}_{\text {Janela corredor }}$ & 0,82 & 0,82 & 0,40 & 0,40 & 0,22 & 0,22 \\
\hline $\mathrm{U}_{\text {Janela interna }}\left[\mathrm{W} / \mathrm{m}^{2} . \mathrm{K}\right]$ & & & 5,82 & 5,82 & 5,77 & 5,77 \\
\hline $\mathrm{TV}_{\text {Janela interna }}$ & & & 0,88 & 0,88 & 0,79 & 0,79 \\
\hline $\mathrm{FS}_{\text {Janela interna }}$ & & & 0,82 & 0,82 & 0,47 & 0,47 \\
\hline Proteção solar & não & não & $\operatorname{sim}$ & $\operatorname{sim}$ & não & $\operatorname{sim}$ \\
\hline Veneziana móvel & não & não & não & $\operatorname{sim}$ & não & $\operatorname{sim}$ \\
\hline $\mathrm{U}_{\text {Parede externa }}\left[\mathrm{W} / \mathrm{m}^{2} . \mathrm{K}\right]$ & 2,47 & 2,47 & 3,1 & 0,39 & 3,1 & 0,39 \\
\hline $\mathrm{U}_{\text {Cobertura }}\left[\mathrm{W} / \mathrm{m}^{2} . \mathrm{K}\right]$ & 2,42 & 2,42 & 0,25 & 0,25 & 0,25 & 0,25 \\
\hline $\mathrm{CT}_{\text {Parede }}\left[\mathrm{kJ} /\left(\mathrm{m}^{2} \mathrm{~K}\right)\right]$ & 200 & 200 & 208 & 116 & 208 & 116 \\
\hline $\mathrm{CT}_{\text {Cobertura }}\left[\mathrm{kJ} /\left(\mathrm{m}^{2} \mathrm{~K}\right)\right]$ & 187 & 187 & 102 & 102 & 102 & 102 \\
\hline$\alpha_{\text {Parede }}$ & 0,65 & 0,65 & 0,25 & 0,25 & 0,25 & 0,25 \\
\hline$\alpha_{\text {Cobertura }}$ & 0,70 & 0,70 & 0,25 & 0,25 & 0,25 & 0,25 \\
\hline Ilum. escritório $\left[\mathrm{W} / \mathrm{m}^{2}\right]$ & 12 & 12 & 9,69 & 9,69 & 9,69 & 9,69 \\
\hline Ilum. corredor $\left[\mathrm{W} / \mathrm{m}^{2}\right]$ & 5 & 5 & 5 & 5 & 5 & 5 \\
\hline $\begin{array}{l}\text { Controle de } \\
\text { iluminação }\end{array}$ & & & dimmer & dimmer & dimmer & dimmer \\
\hline Iluminância escr. [lux] & & & 500 & 500 & 500 & 500 \\
\hline Iluminância corr. [lux] & & & 100 & 100 & 100 & 100 \\
\hline Elevador $\left[\mathrm{W} / \mathrm{m}^{2}\right]$ & 367,5 & 367,5 & 209,1 & 209,1 & 209,1 & 209,1 \\
\hline $\begin{array}{c}\text { Infiltração escr. } \\
\text { [ACH] }\end{array}$ & 1 & 1 & 1 & 0,7 & 1 & 0,7 \\
\hline $\begin{array}{c}\text { Infiltração corr. } \\
{[\mathrm{ACH}]}\end{array}$ & 1 & 1 & 3 & 3 & 3 & 3 \\
\hline $\begin{array}{c}\text { Eficiência [COP, } \\
\text { W/W] }\end{array}$ & 2,8 & 2,8 & 4,31 & 4,31 & 4,31 & 4,31 \\
\hline
\end{tabular}

36 Didoné, E. L.; Wagner, A.; Pereira, F. O. R. 
A Tabela 3 apresenta as áreas das superfícies com módulos e sua potência nominal instalada ${ }^{2}$ para Florianópolis e Fortaleza. Não foram feitas considerações a respeito da distribuição dos módulos e detalhes de instalação.

O balanço térmico para o caso energia zero está apresentado na Figura 6. Para o caso energia zero, as janelas proporcionaram o maior ganho de calor, como no caso protótipo. Isso aconteceu devido ao aumento do tamanho da janela na circulação e do calor adicional gerado pelo $\mathrm{FV}$ semitransparente. Porém, a energia reduzida com iluminação artificial e a eletricidade gerada podem compensar o ganho de calor adicional. De qualquer modo, maior redução no ganho de calor pelas janelas FV é desejável.

\section{Consumo de energia e geração de energia}

O consumo final do edifício de escritórios para os três casos (caso protótipo, caso otimizado e caso energia zero) e a energia produzida pelos módulos fotovoltaicos para o caso energia zero em Florianópolis e em Fortaleza podem ser vistos nas Figuras 7 e 8 .

Para ambas as cidades, aproximadamente a metade do consumo de energia final foi reduzida, a partir do caso protótipo para o caso otimizado. A redução foi aproximadamente de $50 \%$ em Florianópolis e em Fortaleza. Com os casos EEZ a energia excedente de $1 \%$ em Florianópolis e $13 \%$ em Fortaleza pode ser utilizada para alimentar a rede elétrica. Em geral, em Fortaleza o consumo de energia é mais elevado do que em Florianópolis, mas também há mais energia gerada pelos módulos fotovoltaicos.

\section{Balanço energético}

As Figuras 9 e 10 mostram o balanço energético anual para o caso EEZ em Florianópolis e em Fortaleza. As colunas positivas representam o consumo de energia do edifício, e as colunas negativas representam a energia gerada. $\mathrm{O}$ saldo final entre a energia consumida e a gerada para cada mês é representado pelos pontos pretos; os valores negativos significam a energia excedente, que pode ser jogada na rede elétrica.

\section{Energia gerada}

A distribuição da energia gerada de acordo com as diferentes superfícies de instalação fotovoltaica pode ser vista na Figura 11. Os módulos fotovoltaicos da cobertura produziram $35 \%$ da energia em Florianópolis e $38 \%$ em Fortaleza, valores elevados quando comparada a área instalada em relação às outras superfícies. Isso já era esperado devido ao melhor posicionamento dos módulos e à alta eficiência. A soma da energia gerada pelos módulos das fachadas (leste e oeste) corresponde a $44 \%$ e $33 \%$ da energia total produzida. Em Fortaleza os módulos da proteção solar na fachada sul geraram $18 \%$. As janelas com fotovoltaico na fachada norte geraram $21 \% \mathrm{em}$ Florianópolis e $11 \%$ em Fortaleza.

Tabela 3 - Potência fotovoltaica instalada por superfície

\begin{tabular}{l|c|c|c|c|c|c|c|c|c|c}
\hline Superfície & \multicolumn{2}{|c|}{ Cobertura } & \multicolumn{2}{c|}{ Fachada Leste } & \multicolumn{2}{c|}{ Fachada Oeste } & \multicolumn{2}{c|}{ Janela } & \multicolumn{2}{c}{ Proteção Solar } \\
\hline Cidade & $\begin{array}{c}\text { Área } \\
\left(\mathbf{m}^{2}\right)\end{array}$ & $\begin{array}{c}\text { Potência } \\
\text { nominal } \\
\text { instalada } \\
(\mathbf{k W})\end{array}$ & $\begin{array}{c}\text { Área } \\
\left(\mathbf{m}^{2}\right)\end{array}$ & $\begin{array}{c}\text { Potência } \\
\text { nominal } \\
\text { instalada } \\
(\mathbf{k W})\end{array}$ & $\begin{array}{c}\text { Área } \\
\left(\mathbf{m}^{2}\right)\end{array}$ & $\begin{array}{c}\text { Potência } \\
\text { nominal } \\
\text { instalada } \\
(\mathbf{k W})\end{array}$ & $\begin{array}{c}\text { Área } \\
\left(\mathbf{m}^{2}\right)\end{array}$ & $\begin{array}{c}\text { Potência } \\
\text { nominal } \\
\text { instalada } \\
(\mathbf{k W})\end{array}$ & $\begin{array}{c}\text { Área } \\
\left(\mathbf{m}^{2}\right)\end{array}$ & $\begin{array}{c}\text { Potência } \\
\text { nominal } \\
\text { instalada } \\
(\mathbf{k W})\end{array}$ \\
\hline Florianópolis & 138,6 & 27,9 & 214 & 27,8 & 214 & 27,8 & 670 & 20,1 & - & - \\
Fortaleza & 161,7 & 32,5 & 214 & 27,8 & 214 & 27,8 & 670 & 20,1 & 275 & 35,7 \\
\hline
\end{tabular}

Figura 6 - Balanço térmico do edifício para o caso energia zero em (a) Florianópolis e (b) em Fortaleza

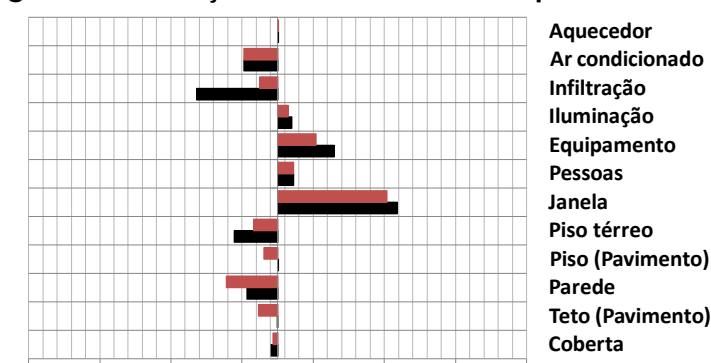

$-70000-50000-30000-1000010000300005000070000$ Fluxo de calor $[\mathrm{kW}]$

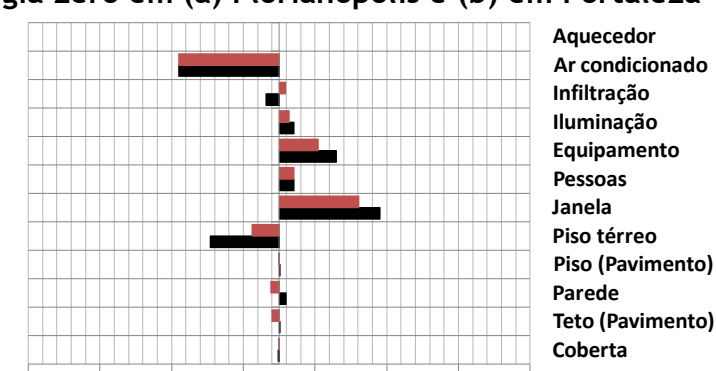

-70000-50000-30000-100001000030000 5000070000 Fluxo de calor [kW]

(a)

Período de ocupação
Total anual 
Figura 7 - Consumo final para Florianópolis

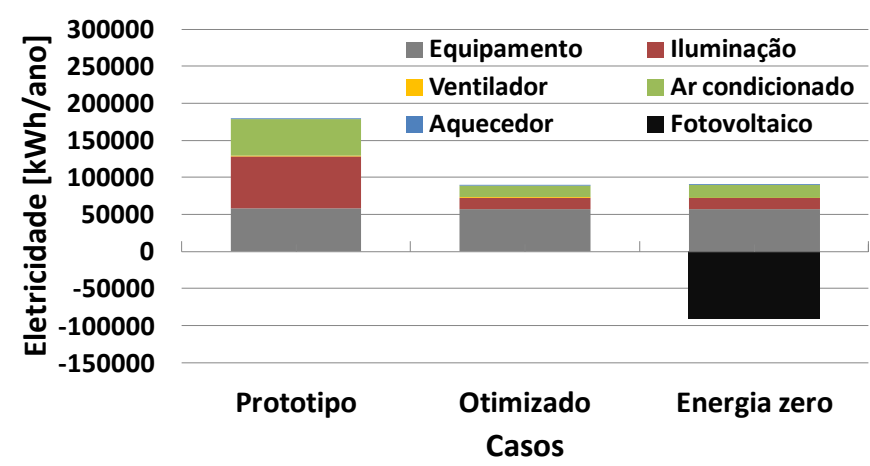

Figura 8 - Consumo final para Fortaleza

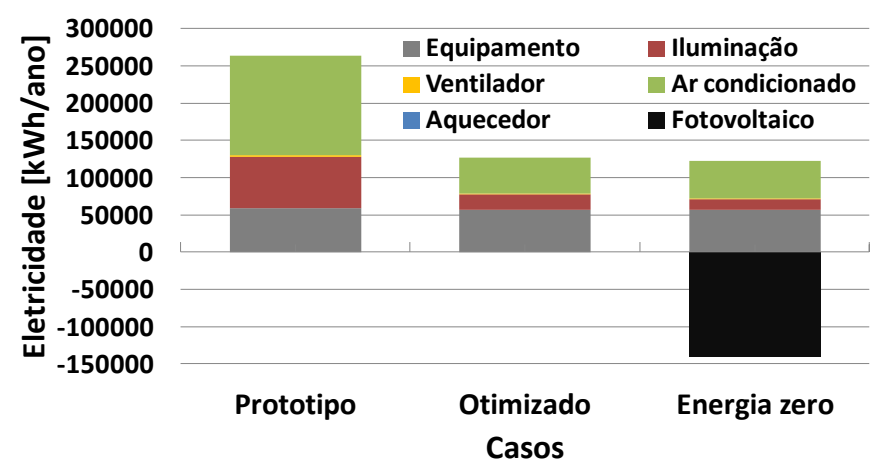

Figura 9 - Balanço energético para o Caso EEZ em Florianópolis

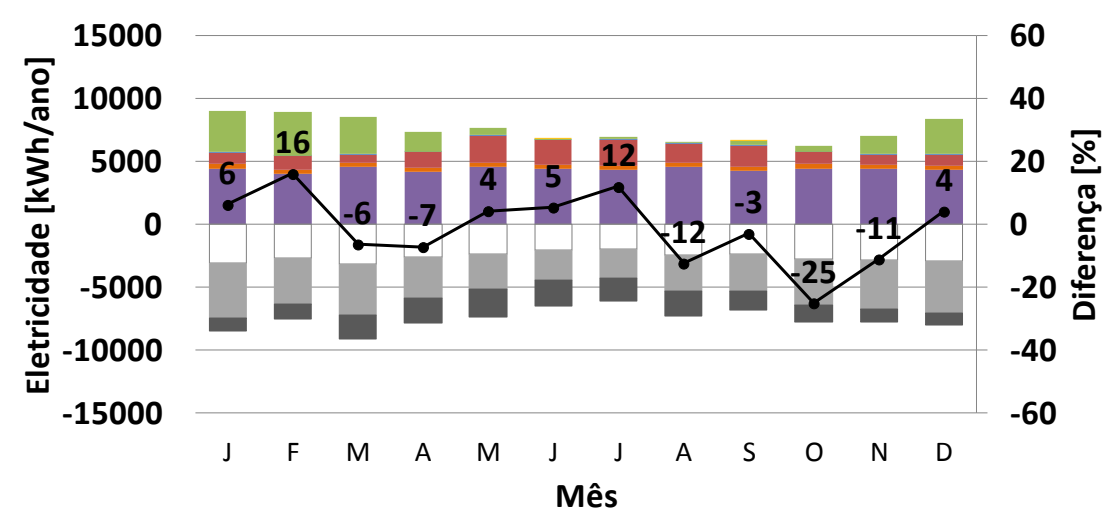

\begin{tabular}{|c|c|c|c|}
\hline Equipamento & Elevador & lluminação & Ventilador \\
\hline Ar condicionado & Aque & $\square$ FV_Coberta & FV_Fachada \\
\hline FV & $\rightarrow[$ & & \\
\hline
\end{tabular}

${ }^{2}$ A potência nominal instalada foi calculada pela eficiência da placa (eficiência x radiação solar/área $x$ área (STC)), dada pelo fabricante, multiplicada pela área do fotovoltaico instalado (DEUTSCHES..., 1999).

38 Didoné, E. L.; Wagner, A.; Pereira, F. O. R. 
Figura 10 - Balanço energético para o Caso EEZ em Fortaleza

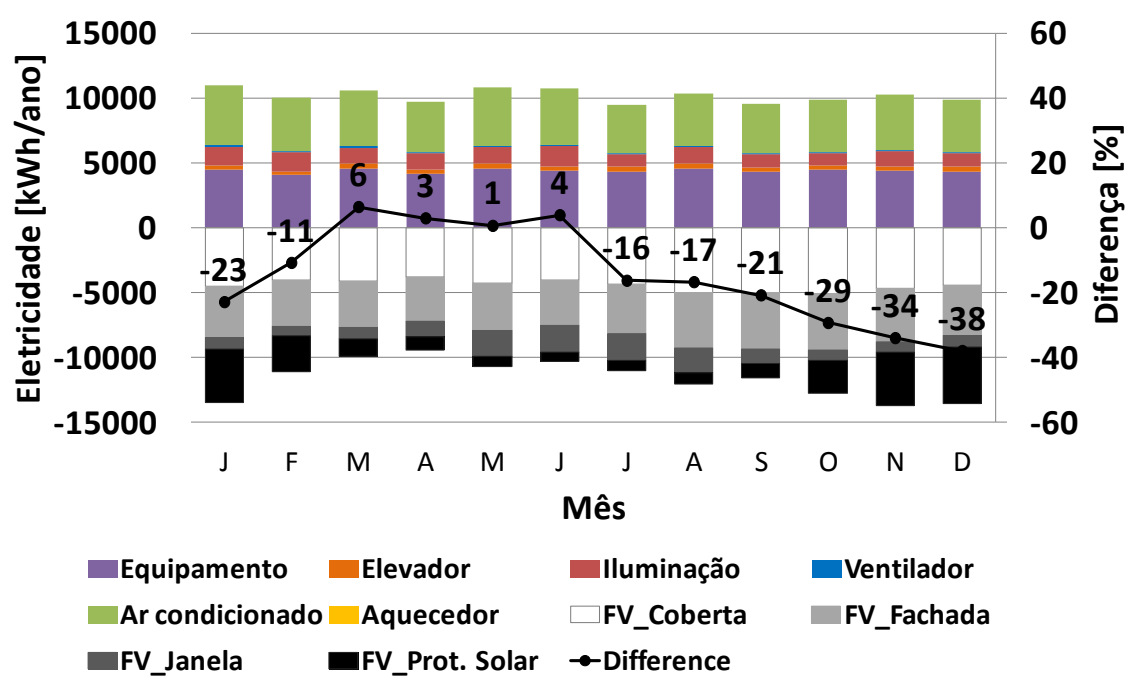

Figura 11 - Energia gerada em diferentes superfícies em (a) Florianópolis e (b) Fortaleza

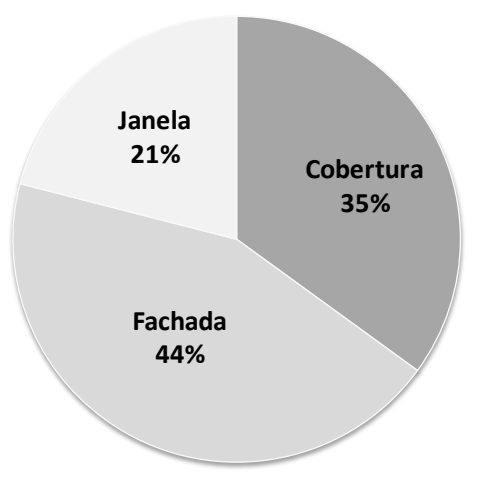

(a)

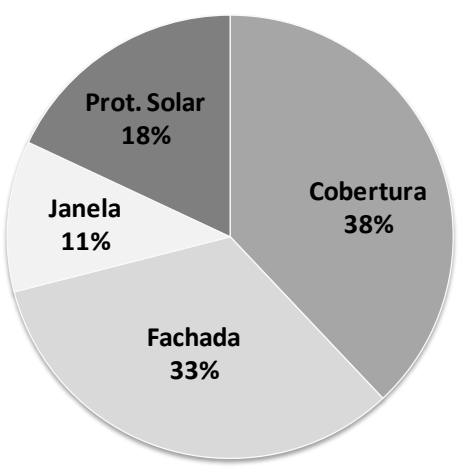

(b)
De acordo com os gráficos, Florianópolis tem menor consumo e geração de energia em junho e julho (inverno). Nestes meses o ar-condicionado é pouco utilizado, e aquecimento não foi necessário. Embora não deva ser considerado como uma estratégia de aquecimento, os ganhos internos foram suficientes para aquecer o edifício nos meses mais frios. Analisando o saldo final de energia, o consumo de energia foi maior do que a energia gerada em 6 meses do ano, havendo energia excedente nos outros 6 meses.

Em Fortaleza, o ar-condicionado é utilizado durante todo o ano. A demanda de energia é maior em Fortaleza do que em Florianópolis, e as diferenças entre os meses de verão e inverno são menores. Mais energia foi produzida em Fortaleza e mais módulos fotovoltaicos foram necessários para satisfazer a demanda energética. Apenas em 4 meses foi utilizada mais energia do que gerada.

\section{Conclusão}

Este artigo apresentou um estudo no qual a contribuição da energia solar para a transformação de edifícios de escritórios brasileiros em edifícios energia zero (EEZ) foi investigada. O foco foi o uso de estratégias para reduzir o consumo energético e a aplicação de tecnologia para diferentes latitudes e climas considerando o ganho de calor, radiação solar e disponibilidade de luz natural.

Os dois climas requerem diferentes estratégias para a redução do consumo e geração de energia. Os cálculos foram focados nos ganhos internos e no envelope do edifício, que sofreram alterações tendo como base o regulamento de eficiência energética para edifícios comerciais no Brasil (RTQ-C). O regulamento se mostrou uma excelente ferramenta, possibilitando uma redução de aproximadamente $50 \%$ do consumo de energia 
em ambas as cidades, porém outras estratégias foram necessárias devido ao uso da janela FV.

Em relação a aplicação fotovoltaica, em Fortaleza, mais módulos puderam ser aplicados na cobertura já que, devido a baixa inclinação $\left(3^{\circ}\right)$, menor foi o espaçamento necessário para evitar o sombreamento entre os módulos. Além disso, o uso de proteção solar possibilitou uma área extra para aplicação FV na envoltória. Contudo, é necessário gerar mais energia em Fortaleza para se obter o balanço zero, devido ao maior consumo de energia que ocorre principalmente com refrigeração. Da mesma forma, em Florianópolis menos tecnologia $\mathrm{FV}$ foi necessária para se obter o caso energia zero, mesmo com menores índices de irradiação solar.

A aplicação de diversas tecnologias fotovoltaicas em diferentes partes da envoltória possibilitou a avaliação de seu potencial quando aplicado em diferentes inclinações e orientações. Grande parte da energia foi gerada pelos fotovoltaicos aplicados na cobertura, com $35 \%$ em Florianópolis e $38 \%$ em Fortaleza. A cobertura é a superfície com menor área de FV instalado, porém, com os módulos com maior eficiência.

A janela com fotovoltaico semitransparente demonstrou ser uma alternativa promissora para a substituição de janelas tradicionais, uma vez que contribuiu com $21 \%$ da energia gerada em Florianópolis e $11 \%$ em Fortaleza, embora os módulos utilizados tenham uma eficiência de apenas 3\%. Nos centros urbanos as janelas com fotovoltaico dos pavimentos inferiores podem ser substituídas por janelas com vidros claros, já que, além de ter menos radiação disponível, devido às obstruções do entorno, deve-se aproveitar mais a pouca luz natural existente.

\section{Referências}

\section{AGÊNCIA NACIONAL DE ENERGIA}

ELÉTRICA. Resolução Normativa n ${ }^{\circ}$ 482, de 17 de abril de 2012. Disponível em

<http://www.aneel.gov.br/>. Acesso em: 7 abr. 2012.

\section{AMERICAN SOCIETY OF HEATING,} REFRIGERATING AND AIRCONDITIONING ENGINEERS. Handbook of Fundamentals. Atlanta, 2005.

\section{ASSOCIAÇÃO BRASILEIRA DE NORMAS} TÉCNICAS. Desempenho Térmico de Edificações: parte 3: zoneamento bioclimático brasileiro e diretrizes construtivas para habitações unifamiliares de interesse social. Rio de Janeiro, 2003.
BARRAUD, E. Stained Glass Solar Windows for the Swiss Tech Convention Center. Mediacon, 2012. Disponível em:

$<$ http://actu.epfl.ch/news/stained-glass-solarwindows-for-the-swiss-tech-con/>. Acesso em: 10 jan. 2013.

BRASIL. Lei n. 10295, de 17 de outubro de 2001, que dispõe sobre a Política Nacional de Conservação e Uso Racional de Energia. Diário Oficial da União, Brasília, 18 de outubro de 2001.

BRASIL. Ministério de Minas e Energia. Eletrobrás. Requisitos Técnicos da Qualidade para o Nível de Eficiência Energética de Edifícios Comerciais, de Serviços e Públicos (RTQ-C). 2010. Versão eletrônica 2. Anexo da Portaria INMETRO n ${ }^{\circ} 372$.

BRASIL. Ministério de Minas e Energia. Eletrobrás. Regulamento Técnico da Qualidade do Nível de Eficiência Energética Edificações Residenciais (RTQ-R). 2012. Versão eletrônica 2. Anexo da Portaria INMETRO n ${ }^{\circ}$ 018/2012.

CARLO, J. C. Desenvolvimento de Metodologia de Avaliação da Eficiência Energética da Envoltória de Edificações Não Residenciais. Florianópolis, 2008. Tese (Doutorado em Engenharia Civil) - Centro Tecnológico, Universidade Federal de Santa Catarina, Florianópolis, 2008.

CHIDIAC, S. E. et al. A Screening Methodology for Implementing Cost Effective Energy Retrofit Measures in Canadian Office Buildings. Energy and Buildings, v. 43, n. 2/3, p. 614-620, 2011.

COLSMANN, A. et al. Efficient Semi-Transparent Organic Solar Cells with Good Transparency Color Perception and Rendering Properties. Advanced Energy Materials, v. 1, p. 599-603, 2011.

DIDONÉ, E. L. A influência da Luz Natural na Avaliação da Eficiência Energética de Edifícios Contemporâneos de Escritórios em Florianópolis/SC. Florianópolis, 2009. Dissertação (Mestrado em Arquitetura e Urbanismo) - Programa de Pós-Graduação em Arquitetura e Urbanismo, Universidade Federal de Santa Catarina, Florianópolis, 2009.

DIDONÉ, E. L.; WAGNER, A. Semi-Transparent PV Window: a study for office buildings in Brazil. Energy and Buildings, v. 67, p. 136-142, 2013.

DEUTSCHES INSTITUT FÜR NORMUNG. DIN EN 61829: Photovoltaische (PV) moduldruppen aus kristallinem Silizium: Messen der Strom/Spannungskennlinien am Einsatzort. Berlin, 1999. 
ENERGYPLUS. Input Output Reference.

Disponível em: <www.EnergyPlus.gov>. Acesso em: 20 jan. 2012a.

\section{ENERGYPLUS. Engineering Reference.}

Disponível em: <www.EnergyPlus.gov>. Acesso em: 20 jan. $2012 b$.

EUROPEAN UNION. Directive 2010/31/EU: of the European Parliament and of the Council of 19 May 2010 on the energy performance of buildings (recast). Disponível em: < http://eur-

lex.europa.eu/LexUriServ/LexUriServ.do?uri=OJ: L:2010:153:0013:0035:EN:PDF>. Acesso em: 2 maio 2012.

\section{FORNYBAR. Solenergi, Fornybar.no:}

information resource for energy systems of the future. NVE, Enova, Norges Forskningsråd and Innovasjon Norge, 2010. Disponível em: <http://www.fornybar.no>. Acesso em: 10 jan. 2013.

HAYTER, S.; TORCELLINI, P.; DERU, M. Photovoltaics For Buildings: new applications and lessons learned. National Renewable Energy Laboratory, 2002.

HUMM, O.; TOGGWEILER, P. Photovoltaik und Architektur: die Integration von Solarzellen in Gebäudehüllen. Basel: Birkhäuser, 1993.

INTERNATIONAL COMMISSION ON ILLUMINATION. ISO/CIE 8995: lighting of indoor work places. Vienna. ISO 2002.

INSTITUTO NACIONAL DE METROLOGIA, QUALIDADE E TECNOLOGIA. Tabela de Consumo/Eficiência Energética: condicionadores de ar split hi-wall. 2014 Disponível em: <http://www.inmetro.gov.br/consumidor/pbe/condi cionador_de_ar_split_hi_wall.pdf.> Acesso em: 30 abr. 2014.

LABORATÓRIO DE ENERGIA SOLAR. Radiasol 2. GESTE/PROMEC, 2013.

LENOIR, A. et al. Towards Net Zero Energy

Buildings in Hot Climate: part 1: new tools and methods. ASHRAE 2011a. Disponível em: $<$ http://task40.ieashc.org/data/sites/1/publications/DC-TP6-Garde2011-11.pdf>. Acesso em: 12 ago. 2014.

LENOIR, A.; THELLIER, F.; GARDE, F. Towards Net Zero Energy Buildings in Hot Climate: part 2: experimental feedback. ASHRAE 2011b. Disponível em: <http://task40.ieashc.org/data/sites/1/publications/DC-TP7-Garde2011-11.pdf>. Acesso em: 12 ago. 2014 (b).

LICHTTECHNISCHES INSTITUT. Personal Information. Karlsruhe University, 2012.
MERCALDO L. V. et al. Thin Film Silicon Phototoltaics: architectural perspectives and technological issues. Applied Energy, v. 86, p. 1836-1844, 2009.

\section{MINISTÉRIO DAS MINAS E ENERGIA.}

Balanço Energético Nacional: 2012. Disponível em: <http://www.mme.gov.br/mme>. Acesso em: 02 jan. 2013.

MUSALL, E. et al. Net Zero Energy Solar

Buildings: an overview and analysis on worldwide building projects. In: EUROPEAN

CONFERENCE, Graz, 2010. Proceedings... Graz, 2010.

NASA. TerraMetrics. Net Zero Energy

Buildings: worldwide. 2013. Disponível em:

<batchgeo.com/map/net-zero-energy-buildings>. Acesso em: 10 jan. 2013.

PETTER JELLE, B.; BREIVIK, C.; DROLSUM RØKENES, H. Building Integrated Photovoltaic Pproducts: a state-of-the-art review and future research opportunities. Solar Energy Materials and Solar Cells, v. 100, 2012.

PROCEL. Programa Nacional de Conservação de Energia Elétrica: áreas de atuação: edificações (PROCEL-Edifica). Disponível em: <http://www.eletrobras.com/>. Acesso em: 10 mar. 2013.

RÜTHER, R. Edifícios Solares Fotovoltaicos. Florianópolis: Labsolar, 2004.

SANTANA, M. V. Influência de Parâmetros Construtivos no Consumo de Energia de Edifícios de Escritório Localizados em Florianópolis - SC. Florianóplis, 2006. Dissertação (Mestrado em Engenharia Civil) Pós-Graduação em Engenharia Civil, Universidade Federal de Santa Catarina, Florianópolis, 2006.

SARTORI, I. et al. Criteria For Definition of Net Zero Energy Buildings. In: International Conference on Solar Heating, Cooling and Buildings, Graz, 2010. Proceedings... Graz, 2010.

SAWIN, J. L. et al. Renewables 2011 global status report, REN21 Secretariat. Paris, 2011. Disponível em: <http://www.ren21.net/>. Acesso em: 10 jan. 2014.

SD EUROPA. Solar Houses 2012. 2012.

Disponível em: <http://www.sdeurope.org/>. Acesso em: $30 \mathrm{dez} .2012$.

SHC Task 40 / Annex 52. Towards Net Zero Energy Solar Buildings. 2008. Disponível em: <http://http://task40.ieashc.org/Data/Sites/11/documents/T40A52Flyer.pdf>. Acesso em: 30 dez. 2012. 
TORCELLINI, P. et al. Zero Energy Buildings: a critical look at the definition. ACEE Summer Study. 2006. Disponível em:

<http://www.biomassthermal.org/programs/docum ents/118_ZEBCriticalLookDefinition.pdf>. Acesso em: 11 ago. 2014.

UNITED STATE DEPARTMENT OF ENERGY. Building Technologies Program, Planned Program Activities For 2008-2012. Disponível em:

$<$ http://apps1.eere.energy.gov/buildings/publicatio ns/pdfs/corporate/myp08complete.pdf >. Acesso em: 12 ago. 2014.

UNITED STATE DEPARTMENT OF ENERGY. EnergyPlus Energy Simulation Software:

weather data. Disponível em:

$<$ http://apps1.eere.energy.gov/buildings/EnergyPlu s/weatherdata_about.cfm>. Acesso em: 3 maio 2012.
VOSS, K.; MUSALL, E.; LICHTMEß, M. From Low-Energy To Net Zero-Energy Buildings: status and perspectives. Journal of Green Building, v. 6, n. 1, p. 46-57, 2011.

\section{ZOMER, C. D. Compromissos Entre Forma e} Função na Geração Solar Fotovoltaica Integrada a Edificações Urbanas. Florianópolis, 2012. Qualificação (Doutorado em Engenharia Civil) - Escola de Engenharia, Universidade Federal de Santa Catarina, Florianópolis, 2012.

\section{Agradecimentos}

Os autores agradecem à Capes e à Eletrobras/Procel, pelo suporte financeiro.

Evelise Leite Didoné

Institute for Building Design and Technology | Karlsruhe Institute of Technology | Englerstr. 7 | D-76131 | Karlsruhe - Alemanha | Tel.: +49 (0) 157 71419697| E-mail.: evelisedidone@gmail.com

\section{Andreas Wagner}

Institute for Building Design and Technology | Karlsruhe Institute of Technology | Tel.: +49 (0) 72160846511 | E-mail.: wagner@kit.edu

\section{Fernando Oscar Ruttkay Pereira}

Departamento de Arquitetura e Urbanismo | Universidade Federal de Santa Catarina | Campus UFSC - Trindade | Florianópolis - SC Brasil | CEP 88040-900 | Tel.: (48) 3721-7080 | E-mail.: ruttkay.pereira@ufsc.br

\section{Revista Ambiente Construído}

Associação Nacional de Tecnologia do Ambiente Construído

Av. Osvaldo Aranha, $99-3^{\circ}$ andar, Centro

Porto Alegre - RS - Brasil CEP $90035-190$

Telefone: +55 (51) 3308-4084

Fax: +55 (51) 3308-4054

www.seer.ufrgs.br/ambienteconstruido

E-mail: ambienteconstruido@ufrgs.br 